\title{
Percutaneous fixation with Kirschner wires versus volar locking plate fixation in adults with dorsally displaced fracture of distal radius: randomised controlled trial
}

\author{
(c) $\underset{1}{(1)(8)}$ OPEN ACCESS
}

Matthew L Costa professor of trauma and orthopaedic surgery ${ }^{12}$, Juul Achten senior research fellow $^{12}$, Nick R Parsons medical statistician ${ }^{3}$, Amar Rangan professor of trauma and orthopaedic surgery $^{4}$, Damian Griffin professor of trauma and orthopaedic surgery ${ }^{12}$, Sandy Tubeuf lecturer in health economy ${ }^{5}$, Sarah E Lamb professor of rehabilitation ${ }^{6}$, on behalf of the DRAFFT Study Group

${ }^{1}$ Warwick Clinical Trials Unit, University of Warwick, Coventry CV4 7AL, UK; ${ }^{2}$ University Hospitals Coventry and Warwickshire NHS Trust, Coventry CV2 2DX, UK; ${ }^{3}$ Clinical Sciences Research Laboratories, University of Warwick, Coventry CV2 2DX, UK; ${ }^{4}$ Wolfson Research Institute, School of Medicine and Health, Durham University, Queen's Campus, Stockton-on-Tees TS17 6BH, UK; ${ }^{5}$ Leeds Institute of Health Sciences, Leeds University, Leeds LS2 9LJ, UK; ${ }^{6}$ Nuffield Department of Orthopaedics, Rheumatology and Musculoskeletal Sciences, University of Oxford, Nuffield Orthopaedic Centre, Oxford OX3 7HE, UK

\begin{abstract}
Objectives To compare the clinical effectiveness of Kirschner wire fixation with locking plate fixation for patients with a dorsally displaced fracture of the distal radius.

Design A multicentre two arm parallel group assessor blind randomised controlled trial with 1:1 treatment allocation.

Setting 18 trauma centres in the United Kingdom.

Participants 461 adults with a dorsally displaced fracture of the distal radius within $3 \mathrm{~cm}$ of the radiocarpal joint that required surgical fixation. Patients were excluded if the surgeon thought that the surface of the wrist joint was so badly displaced it required open reduction.

Interventions Kirschner wire fixation: wires are passed through the skin over the dorsal aspect of the distal radius and into the bone to hold the fracture in the correct anatomical position. Locking plate fixation: a locking plate is applied through an incision over the volar (palm) aspect of the wrist and secured to the bone with fixed angle locking screws.

Main outcome measures Primary outcome measure: validated patient rated wrist evaluation (PRWE). This rates wrist function in two (equally weighted) sections concerning the patient's experience of pain and disability to give a score out of 100 . Secondary outcomes: disabilities of arm, shoulder, and hand (DASH) score, the EuroQol (EQ-5D), and complications related to the surgery.
\end{abstract}

Results The baseline characteristics of the two groups were well balanced, and over $90 \%$ of patients completed follow-up. The wrist function of both groups of patients improved by 12 months. There was no clinically relevant difference in the patient rated wrist score at three, six, or 12 months (difference in favour of the plate group was $-1.3,95 \%$ confidence interval -4.5 to $1.8 ; P=0.40$ ). Nor was there a clinically relevant difference in health related quality of life or the number of complications in each group.

Conclusions Contrary to the existing literature, and against the rapidly increasing use of locking plate fixation, this trial found no difference in functional outcome in patients with dorsally displaced fractures of the distal radius treated with Kirschner wires or volar locking plates. Kirschner wire fixation, however, is cheaper and quicker to perform.

Trial registration Current Controlled Trials ISCRTN 31379280. UKCRN 8956.

\section{Introduction}

Fractures of the distal radius are extremely common. In the Western world, for example, $6 \%$ of women will have sustained such a fracture by the age of 80 and $9 \%$ by the age of $90 .{ }^{1}$ All age groups are affected; younger patients often sustain complicated high energy injuries involving the wrist joint, but fractures of the distal radius are also common in older patients, 
who are more likely to sustain low energy fractures related to osteoporosis. $^{2}$

Fractures of the distal radius are treated non-operatively if the bone fragments can be held in anatomical alignment (reduction) by a plaster cast or orthotic. If this is not possible, surgical fixation is performed. This carries inherent risks for the patient and considerable cost implications; much of this cost is related to the choice of fixation. ${ }^{3}$

A summary of evidence from the Cochrane Collaboration "exposed the serious deficiency in the available evidence" in the treatment of distal radius fractures, including "what type of surgery is indicated." ${ }^{4}$ The two most common forms of surgical fixation are Kirschner wire fixation and locking plate fixation.

Kirschner wire fixation is a longstanding technique in which smooth metal wires with a sharp point are passed across the fracture site through the skin. This technique is rapidly being superseded by locking plate fixation, in which a plate is attached to the bone with fixed angle screws. ${ }^{5}$ Locking plates are widely considered to provide stronger fixation, which facilitates earlier return to normal activities. This potential benefit is said to justify the greater cost of the plates. ${ }^{5}$ To date, studies comparing the two methods have indicated that locking plates provide improved radiological and/or functional outcomes, particularly in the early stages of rehabilitation; though these studies were smaller single centre trials. ${ }^{6-10}$

In this multicentre randomised trial, the distal radius acute fracture fixation trial (DRAFFT) ${ }^{11}$ we examined Kirschner wire fixation compared with volar locking plate fixation for patients with a dorsally displaced fracture of the distal radius. Our hypothesis was that locking plates would provide improvements in the patient rated wrist evaluation (PRWE) score in the 12 months after surgery.

\section{Methods}

\section{Study population}

We enrolled patients from 18 centres in the United Kingdom; all trauma centres and surgeons included in the trial, and indeed in the UK, use both Kirschner wires and locking plates for distal radius fractures. The trial centres included both major trauma centres and smaller emergency hospitals.

Study participants were aged 18 or over and had a dorsally displaced fracture of the distal radius within $3 \mathrm{~cm}$ of the radiocarpal joint. The only other inclusion criterion was that the treating surgeon believed that the patient would benefit from surgical fixation of the fracture.

Patients were excluded if they presented more than two weeks after the injury, if the fracture extended more than $3 \mathrm{~cm}$ from the radiocarpal joint, if the fracture was open (Gustilo grading $>1^{12}$ ), if the articular surface of the fracture could not be reduced by indirect techniques (in some fractures, the joint surface is so badly disrupted that the surgeon will have to open up the fracture to restore the anatomy under direct vision), if there was a contraindication to anaesthesia, or if the patient was unable to complete questionnaires.

\section{Outcome measures}

Patients' characteristics and baseline (pre-injury) functional status were self reported after they consented to take part in the trial. The primary outcome measure was the validated patient rated wrist evaluation (PRWE). ${ }^{13}$ This rates wrist function in two (equally weighted) sections concerning the patient's experience of pain and disability to give a score out of 100 (with
100 being the worst score). The PRWE, and secondary measures, were collected by postal questionnaire at baseline and at three, six, and 12 months after surgery. The PRWE is the most sensitive outcome measure for patients sustaining this specific injury. ${ }^{14}$

The secondary outcome measures were the disabilities of arm, shoulder, and hand (DASH) score, health related quality of life measured with the EuroQol (EQ-5D), complications related to the surgery, and resource use (reported elsewhere). DASH is a 30 item self report questionnaire (0-100, with 100 indicating greater disability) designed to provide a general measure of physical function and symptoms in people with disorders of the upper limb. ${ }^{15}$ The EQ-5D is a validated generalised quality of life questionnaire consisting of five domains of health; patients' responses can be converted to health state utility values, ${ }^{16}$ anchored at 1 (perfect health) and 0 (death). ${ }^{17}$ Complications were grouped as refracture, neurological injury, vascular injury, tendon injury, superficial wound infection, and deep wound infection.

\section{Study treatments}

All of the selected hospitals and the surgeons involved in the trial were familiar with both fixation techniques. Although the basic principles of Kirschner wire fixation and locking plate fixation are inherent in the design of the implants, there are several different implant systems and several different options for the positioning of wires and screws; the details of the surgery were left to the discretion of the surgeon to ensure that the results of the trial could be generalised to as wide a group of patients as possible. All patients underwent a routine preoperative assessment and had surgery under general anaesthetic.

In Kirschner wire fixation, the wires are passed through the skin over the dorsal aspect of the distal radius and into the bone to hold the fracture in the correct (anatomical) position. The size and number of wires, the insertion technique, and the configuration of wires were decided by the surgeon. A plaster cast was applied to supplement the wire fixation as per usual surgical practice.

In locking plate fixation, the locking plate is applied through an incision over the volar (palm) aspect of the wrist. The details of the surgical approach, the type of plate, and the number and configuration of screws were decided by the surgeon. The only stipulation was that the screws in the distal portion of the bone were "fixed angle" - that is, screwed into the plate-but this is the standard technique for the use of these plates. Some surgeons use a temporary plaster cast after the procedure, but the fixed angle stability provided by the locking plate is generally sufficient to allow early controlled range of movement exercises. The use or otherwise of a cast was again at the discretion of the surgeon.

All patients received the same standardised written physiotherapy advice; both groups were advised to move their shoulder, elbow, and finger joints fully within the limits of their comfort. Patients in the Kirschner wire group were encouraged to perform range of movement exercises at the wrist as soon as their plaster cast was removed. Patients in the locking plate group were encouraged to begin the exercises immediately if they did not have a plaster cast or as soon as the cast was removed. Any other rehabilitation input beyond the written information sheet (including a formal referral to physiotherapy) was left to the discretion of the treating surgeon, but a record of any other investigations/interventions was recorded. 


\section{Randomisation}

After participants gave informed consent, a secure centralised telephone randomisation service was used to allocate the method of fixation. The randomisation sequence was generated and administered at an independent clinical trials unit (York, UK) to ensure that allocation was concealed. Randomisation was on a 1:1 basis, stratified by centre, intra-articular extension of the fracture, and age of the patient.

Stratification by centre ensured that any clustering effect on the study outcomes related to the centre itself was equally distributed in the trial arms. Stratification on the basis of intra-articular extension of the fracture (specifically involvement of the articular surface of the radiocarpal joint) eliminated a major potential confounder as disruption of this articular surface can predispose to secondary osteoarthritis of the wrist. ${ }^{5}$ We used stratification on the basis of age $(\geq 50$ or $<50)$ to balance between the intervention groups the number of younger patients with normal bone quality sustaining high energy fractures and older patients with low energy (fragility) fractures related to osteoporosis. Age was therefore used as a surrogate for bone density as bone mineral density of the forearm remains stable up until the age of $50 .^{18}$

\section{Blinding}

The operating surgeon could not be blind in the trial and, as the Kirschner wires protrude on the back of the wrist and the locking plate require an incision, nor could the patient. All staff involved in checking, entering, and analysing questionnaire responses, however, were blind to allocation.

\section{Sample size and statistical analysis}

The primary outcome measure was the patient rated wrist evaluation (PRWE) score at 12 months. ${ }^{13}$ A 6 point difference in the PRWE equates to a standardised effect size of 0.3 , for an assumed standard deviation (SD) of 20 points. ${ }^{19}$ MacDermid and colleagues found that the PRWE is sensitive enough to detect subtle but clinically relevant changes in wrist function of this order of magnitude in patients sustaining a fracture of the distal radius, such as changes seen between three and six months. ${ }^{14}$ At the individual level, a change in the PRWE of 6 points reflects the difference between turning a doorknob or cutting a loaf of bread with mild pain versus no pain.

A 6 point difference between groups at the $5 \%$ level with $80 \%$ power required 175 patients in each group - that is, 350 patients in total. With an allowance for a conservative $10 \%$ loss to follow-up, we planned to recruit 390 patients. As a result of faster than expected recruitment to the trial, and with the permission of the review board, however, we were able to recruit 461 patients.

Differences between treatment groups were assessed on an intention to treat basis, with a normal approximation for the PRWE score at three, six, and 12 months. Preplanned subgroup analyses for PRWE were based on the stratification by intra-articular extension and age $\geq 50$ or $<50$. A secondary analysis based on the type of fixation provided (per treatment analysis) was also preplanned. We anticipated using a multilevel model to account for both surgeon and centre effects, but as most of the surgeons $(88 \% ; 215 / 244)$ operated on fewer than three patients, we used mixed effects linear regression models with a single random effect to account for recruiting centre to analyse the primary and secondary outcome measures. An analogously structured logistic regression model was used to analyse complications. Tests were two sided and considered to provide evidence for a significant difference if $\mathrm{P}<0.05$ (5\% significance level).

For missing data we used multiple imputations via chained equations,${ }^{20}$ with pooled estimates of model parameters based on 50 data imputations. ${ }^{21}$ The statistical analysis plan was agreed with the independent data management committee at the start of the study. All statistical analysis was carried out with $\mathrm{R}^{22}$

\section{Results \\ Patients}

From January 2011 to July 2012, we randomised 461 patients (fig 1). $\Downarrow$ During the recruitment period, 178 potentially eligible patients were unwilling to take part; the main reasons were unwillingness to be part of a research project (55 patients; $31 \%$ ), preference for Kirschner wire fixation $(26 ; 15 \%)$, or preference for plate fixation $(29 ; 16 \%)$. Of the 230 patients assigned to Kirschner wires, $208(90 \%)$ had the allocated treatment, and of the 231 patients assigned to locking plate fixation, 213 (92\%) were treated as allocated.

The baseline characteristics, wrist function before surgery, and quality of life of the two groups were similar (table 1). $\Downarrow$ The mean age (SD) of the 178 potentially eligible but unwilling patients was 56.1 (SD 18.8) and 79\% (141) were women. This suggests that the study population was broadly representative of the wider population of patients with distal radius fracture in the UK.

Treatments were undertaken by 244 different surgeons; the median number of operations per surgeon was 1 (interquartile range 1-2). Table 2 shows the details of the surgeons and the operations. $\Downarrow$ Of note, the surgical time for the Kirschner wire fixation was shorter than for locking plate, with a median difference of 31 minutes (95\% confidence interval 28 to 35 minutes; Mann-Whitney test $\mathrm{P}<0.001)$.

The rate of peri-operative antibiotic use was higher in the plate group than in the Kirschner wire group; $83 \%$ v $71 \%$ of study participants were prescribed antibiotics (estimated odds ratio $3.5,95 \%$ confidence interval 2.0 to 6.5; Fisher's exact test $\mathrm{P}<0.001$ ) (table $2 \Downarrow$ ).

\section{Primary outcome}

Figure 2 shows the PRWE scores for the two study groups at baseline (before injury) and at three, six, and 12 months. $\Downarrow$ Wrist scores improved in the postoperative period in both groups, but function at 12 months was still about $15 \%$ worse than before the injury.

There was no evidence for a significant difference in PRWE scores between the treatment groups at any time point. The adjusted estimate of the treatment effect for the PRWE score at 12 months after surgery was -1.3 (95\% confidence interval -4.5 to $1.8 ; \mathrm{P}=0.40$ from an $\mathrm{F}$ test for the treatment group factor from the model analysis of variance (ANOVA)). A negative value for the effect size estimate indicates improved function in the locking plate group.

Patients aged over 50 formed a sizeable subgroup (74\%; $341 / 461$ ), so this was identified a priori as being of particular interest. The adjusted estimate of the treatment effect in this age group was -2.2 (95\% confidence interval -5.8 to 1.4$)$ in favour of the plate group; $\mathrm{P}=0.338$ ( $\mathrm{F}$ test from ANOVA) indicates that there is no evidence for a significant interaction term between age group and treatment. Similarly, there was no evidence of a clinically relevant difference between treatments in those patients with an intra-articular fracture: the adjusted 
estimate of the treatment effect was 0.7 ( -3.8 to 5.2) in favour of the wire group. Table 3 shows full details, including the other preplanned subgroup analyses for the primary outcome. $\Downarrow$

\section{Secondary analyses}

There was evidence for a marginally significant $(\mathrm{P}=0.051)$ treatment effect in favour of the plate group for the DASH score at 12 months only, although the effect size was small $-3.2(95 \%$ confidence interval -6.5 to 0.0 ). EQ-5D failed to show any significant differences between treatment groups.

The per treatment analysis (according to the fixation performed) gave an adjusted treatment effect estimate of $-1.0(95 \%$ confidence interval -4.2 to $2.2 ; \mathrm{P}=0.53)$ for PRWE and -3.1 ( -6.3 to $0.2 ; \mathrm{P}=0.066$ ) for DASH.

There were 46 participants with missing primary outcome data at the 12 month study endpoint; the data were $90.0 \%(415 / 461)$ complete. The pooled estimates of the treatment group effect with imputed data were -1.2 (95\% confidence interval -4.2 to 1.9) for PRWE and -3.2 (-6.2 to -0.1) for DASH, with the percentage of the variability attributable to the uncertainty caused by the missing data, estimated at $5.8 \%$ and $5.5 \%$ for the two outcome measures, respectively. In summary the inferences based on the complete data, after imputation, are not markedly different from those reported from the complete case analysis in table 3. $\Downarrow$

There was no evidence to suggest that rates of any complications differed between study groups, based on comparing counts in groups. As expected, more patients in the Kirschner wire group were given a cast after the operation, and subsequently that group had more plaster changes (table 4 ). $\Downarrow$

\section{Discussion}

\section{Principle findings}

Despite the expense associated with locking plate fixation of distal radius fractures, millions of patients have been treated with this method around the world. In this trial, we have shown that locking plates offer no advantage over the older and cheaper method of Kirschner wire fixation for patients with dorsally displaced fractures of the distal radius.

As the confidence intervals exclude the minimum clinically important difference for the patient rated wrist evaluation (PRWE), we conclude that any difference in functional scores between treatment groups is unlikely to be important to patients. Furthermore, secondary clinical outcomes show that there is no clinically relevant difference between the groups in terms of health related quality of life or the risk of complications. There was a borderline significant difference in the disabilities of arm, shoulder and hand (DASH) at one time point (12 months) in favour of the locking plate, but this was well below the minimum clinically important difference. ${ }^{23}$ Kirschner wire fixation, however, requires significantly shorter surgical operating time than locking plate fixation and a reduced use of perioperative antibiotics.

This large multicentre trial contradicts both the rapidly increasing use of locking plates in the treatment of distal radius fractures and the conclusions from previous trials that suggested that locking plates provide improved functional outcomes, ${ }^{7-9}$ particularly in the early stages of rehabilitation. The previous trials were smaller single centre studies.

\section{Limitations and strengths}

The main limitation of our trial is that we could not blind either the surgeons or the patients to the study treatments. It could be argued, however, that this is a positive feature in a pragmatic trial as patients would know about their proposed treatment before surgery during routine care. ${ }^{24}$ It should be noted that this study excluded patients in whom the surface of the wrist (radiocarpal) joint could not be reduced by indirect means- that is, the results should not be generalised to the small minority of patients whose fracture requires that the surgeon opens the joint surface to expose the individual bone fragments to restore the congruity of the wrist joint.

Compliance with the trial was good, with over $90 \%$ of patients receiving their allocated treatment. Some patients did cross over to have a different form of fixation, but an analysis by treatment given did not alter the results. The long term outcome of patients with a fracture of the distal radius is not known. Our data suggest that patients' wrist function and quality of life improves over the 12 months after their surgery but does not return to levels before the injury. The patients in this trial will be followed up annually to determine the prevalence of late complications such as arthritis.

\section{Conclusions}

In conclusion, and in contrast to both the trend in surgical practice and the findings of previous studies, we found no difference in patient rated wrist evaluation in the 12 months after Kirschner wire fixation versus volar locking plate fixation. Kirschner wire fixation is cheaper and quicker to perform.

We thank all those involved in making DRAFFT a success, including the patients and the research associates at all the research sites and in particular Jaclyn Brown, Isabel Wall, and Susie Hennings for their input in trial coordination and management and Caroline Plant for the analysis of patients' radiographs.

\section{DRAFFT Study Group}

Alison Edwards, Keith Willett, Damian Griffin, Tim Chesser, Phillip Johnson, Joe Dias, Jaime Candal-Couto, Srinivasan Makaram, Andrew Gray, Kevin Smith, Sameer Gidwani, Jonathon Jones, Simon Richards, David Gidden, Callum Clark, Rajesh Nanda, Chris Roberts.

Contributors: MLC, NRP, and JA were responsible for the trial design with substantial clinical and trial management input from AR, DG, ST, and SEL. MLC and JA were responsible for acquisition of data. NRP was responsible for the statistical analysis. All authors were responsible for the interpretation of the data and for drafting and approving the final submitted manuscript. MLC is guarantor.

Funding: This study was funded through the Health Technology Assessment scheme of the NIHR (HTA08/116/97). This manuscript presents independent research commissioned by the National Institute for Health Research. The views expressed are those of the authors and not necessarily those of the NHS, the NIHR or the Department of Health. This trial was co-sponsored by the University of Warwick and University Hospitals Coventry and Warwickshire NHS trust.

Competing interests: All authors have completed the Unified Competing Interest form at www.icmje.org/coi_disclosure.pdf (available on request from the corresponding author) and declare: no support from any organisation for the submitted work; consultant surgeons involved in this study have received research project funding and provided paid educational support to meetings sponsored by manufacturers of trauma implants but not in relation to this study.

Ethical approval: This study approved by the Coventry research ethics committee under reference number 10/H1210/10. Approval was obtained from the research and development department of UHCW NHS trust. 


\section{What is already known on this topic}

Fractures of the distal radius are extremely common, and a substantial proportion require surgical fixation

Kirschner wire fixation is a longstanding technique in which smooth metal wires with a sharp point are passed across the fracture site through the skin

This technique is rapidly being superseded by locking plate fixation, in which a plate is attached to the bone with fixed angle screws

\section{What this study adds}

Locking plates offer no clinically relevant advantage with regards to wrist function or quality of life over the older method of Kirschner wire fixation

Kirschner wire fixation is cheaper and quicker to perform

The published protocol ${ }^{11}$ was approved by the NHS ethical review board and each institution's research board. All patients provided informed consent before inclusion.

Transparency: The corresponding author affirms that this manuscript is an honest, accurate, and transparent account of the study being reported; that no important aspects of the study have been omitted; and that any discrepancies from the study as planned and registered have been explained.

Data sharing: No additional data available.

1 Barrett JA, Baron JA, Karagas MR, Beach ML. Fracture risk in the US Medicare population J Clin Epidemiol 1999;52:243-9.

2 Chen NC, Jupiter JB. Management of distal radial fractures. J Bone Joint Surg Am 2007;89:2051-62.

3 Kakarlapudi TK, Santini A, Shahane SA, Douglas D. The cost of treatment of distal radial fractures. Injury 2000;31:229-32.

4 Handoll HH, Madhok R. From evidence to best practice in the management of fractures of the distal radius in adults: working towards a research agenda. BMC Musculoskelet Disord 2003;4:27.

5 Downing ND, Karantana A. A revolution in the management of fractures of the distal radius? J Bone Joint Surg Br 2008:90:1271-5.

6 Karantana A, Downing ND, Forward DP, Hatton M, Taylor AM, Scammell BE, et al. Surgical treatment of distal radial fractures with a volar locking plate versus conventional percutaneous methods: a randomized controlled trial. J Bone Joint Surg Am 2013;95:1737-44.

7 Rozental TD, Blazar PE, Franko OI, Chacko AT, Earp BE, Day CS. Functional outcomes for unstable distal radial fractures treated with open reduction and internal fixation or closed reduction and percutaneous fixation. A prospective randomized trial. J Bone Joint Surg Am 2009;91:1837-46.

8 Marcheix PS, Dotzis A, Benko PE, Siegler J, Arnaud JP, Charissoux JL. Extension fractures of the distal radius in patients older than 50: a prospective randomized study comparing fixation using mixed pins or a palmar fixed-angle plate. $J$ Hand Surg Eur Vol 2010;35:646-51.

9 McFadyen I, Field J, McCann P, Ward J, Nicol S, Curwen C. Should unstable extra-articula distal radial fractures be treated with fixed-angle volar-locked plates or percutaneous Kirschner wires? A prospective randomised controlled trial. Injury 2011;42:162-6.

10 Hollevoet N, Vanhoutie T, Vanhove W, Verdonk R. Percutaneous K-wire fixation versus palmar plating with locking screws for Colles' fractures. Acta Orthop Belg 2011;77:180-7.
11 Costa ML, Achten J, Parsons NR, Rangan A, Edlin RP, Brown J, et al. UK DRAFFT—a randomised controlled trial of percutaneous fixation with Kirschner wires versus volar locking-plate fixation in the treatment of adult patients with a dorsally displaced fracture of the distal radius. BMC Musculoskelet Disord 2011;12:201.

12 Gustilo RB, Anderson JT. Prevention of infection in the treatment of one thousand and twenty-five open fractures of long bones: retrospective and prospective analyses. J Bone Joint Surg Am 1976;58:453-8.

13 MacDermid JC, Turgeon T, Richards RS, Beadle M, Roth JH. Patient rating of wrist pain and disability: a reliable and valid measurement tool. J Orthop Trauma 1998;12:577-86.

14 MacDermid JC, Richards RS, Donner A, Bellamy N, Roth JH. Responsiveness of the short form-36, disability of the arm, shoulder, and hand questionnaire, patient-rated wrist evaluation, and physical impairment measurements in evaluating recovery after a distal radius fracture. J Hand Surg Am 2000;25:330-40.

15 Hudak PL, Amadio PC, Bombardier C. Development of an upper extremity outcome measure: the DASH (disabilities of the arm, shoulder and hand). The Upper Extremity Collaborative Group (UECG). Am J Ind Med 1996;29:602-8.

16 Dolan P. Modeling valuations for EuroQol health states. Med Care 1997;35:1095-108.

17 Brooks R. EuroQol: the current state of play. Health Policy 1996;37:53-72.

18 Berntsen GK, Fonnebo V, Tollan A, Sogaard AJ, Magnus JH. Forearm bone mineral density by age in 7,620 men and women: the Tromso study, a population-based study. Am J Epidemiol 2001;153:465-73.

19 MacDermid JC, Roth JH, Richards RS. Pain and disability reported in the year following a distal radius fracture: a cohort study. BMC Musculoskelet Disord 2003;4:24.

20 White IR, Royston P, Wood AM. Multiple imputation using chained equations: issues and guidance for practice. Stat Med 2011;30:377-99.

21 Rubin DB. Multiple imputation for nonresponse in surveys. John Wiley, 1987.

22 Team RC. R: a language and environment for statistical computing. R Foundation for Statistical Computing, 2013

23 Beaton DE, van Eerd D, Smith P, van der Velde G, Cullen K, Kennedy CA, et al. Minimal change is sensitive, less specific to recovery: a diagnostic testing approach to interpretability. J Clin Epidemiol 2011;64:487-96.

24 Schwartz D, Lellouch J. Explanatory and pragmatic attitudes in therapeutical trials. J Clin Epidemiol 2009:62:499-505.

\section{Accepted: 17 July 2014}

\section{Cite this as: BMJ 2014;349:g4807}

This is an Open Access article distributed in accordance with the Creative Commons Attribution Non Commercial (CC BY-NC 3.0) license, which permits others to distribute, remix, adapt, build upon this work non-commercially, and license their derivative works on different terms, provided the original work is properly cited and the use is

non-commercial. See: http://creativecommons.org/licenses/by-nc/3.0/. 


\section{Tables}

Table 1| Baseline characteristics of $\mathbf{4 6 1}$ study participants by treatment group (Kirschner wires or volar locking plate fixation). Figures are numbers (percentage) unless stated otherwise*

\begin{tabular}{|c|c|c|}
\hline & Wire $(n=230)$ & Plate $(n=231)$ \\
\hline Men & $39(17)$ & $37(15)$ \\
\hline Intra-articular extension & $108(47)$ & $109(47)$ \\
\hline Mean (SD) age (years) & $59.7(16.4)$ & $58.3(14.9)$ \\
\hline \multicolumn{3}{|l|}{ Side of injury: } \\
\hline Right & $101(44)$ & $101(44)$ \\
\hline Left & $123(53)$ & $124(54)$ \\
\hline \multicolumn{3}{|l|}{ Handedness of patient: } \\
\hline Right & $196(85)$ & $202(87)$ \\
\hline Left & $32(14)$ & $26(11)$ \\
\hline Previous problem on injured side & $33(14)$ & $39(17)$ \\
\hline \multicolumn{3}{|l|}{ Mechanism of injury: } \\
\hline Low energy fall & $190(83)$ & $189(82)$ \\
\hline High energy fall & $36(16)$ & $36(16)$ \\
\hline Road traffic collision & $1(0)$ & $4(2)$ \\
\hline Crush & $1(0)$ & $0(0)$ \\
\hline Other & $2(1)$ & $2(1)$ \\
\hline \multicolumn{3}{|l|}{ Fracture classificationt: } \\
\hline $\mathrm{A} 1, \mathrm{~A} 2, \mathrm{~A} 3$ & $0,73,84(69)$ & $0,71,78(65)$ \\
\hline $\mathrm{B} 1, \mathrm{~B} 2, \mathrm{~B} 3$ & $1,1,1(1)$ & $4,1,0(2)$ \\
\hline $\mathrm{C} 1, \mathrm{C} 2, \mathrm{C} 3$ & $33,26,7(29)$ & $30,34,11(33)$ \\
\hline Mean (SD) BMI & $24.8(4.0)$ & $26.5(5.3)$ \\
\hline Osteoporosis & $22(10)$ & $20(9)$ \\
\hline Regular analgesia & $70(30)$ & $61(26)$ \\
\hline Smoker & $50(22)$ & $42(18)$ \\
\hline \multicolumn{3}{|l|}{ Alcohol consumption (units/week): } \\
\hline $0-7$ & $164(71)$ & $164(71)$ \\
\hline 8-14 & $39(17)$ & $45(19)$ \\
\hline $15-21$ & $16(7)$ & $14(6)$ \\
\hline$>21$ & $11(5)$ & $8(3)$ \\
\hline \multicolumn{3}{|c|}{ Mean (SD) scores before injury (retrospectively): } \\
\hline PRWE & $2.6(8.4)$ & $2.8(8.7)$ \\
\hline DASH & $5.4(12.7)$ & $4.6(10.8)$ \\
\hline$E Q-5 D$ & $0.92(0.17)$ & $0.94(0.15)$ \\
\hline
\end{tabular}

*Where totals for categorical variables do not sum to treatment group totals, it indicates that some data were missing.

†A1: extra-articular, ulnar fracture with intact radius; A2: extra-articular, radius fracture, simple or impacted; A3: extra-articular multiple fragmented fracture; B1: partial articular fracture in sagittal plane; B2: partial articular fracture in coronal plane with dorsal fragment; B3: partial articular fracture in coronal plane with volar fragment; $\mathrm{C} 1$ : complete articular fracture, articular simple and metaphyseal simple; C2: complete articular fracture, articular simple but multiple fragmented metaphyseal; C3: complete articular fracture, multiple fragmented articular and metaphyseal. 


\begin{tabular}{|c|c|c|}
\hline & Wire $(n=230)$ & Plate $(n=231)$ \\
\hline \multicolumn{3}{|l|}{ Surgeon grade: } \\
\hline Consultant & $60(26)$ & $71(31)$ \\
\hline Specialist trainee & $102(44)$ & $106(46)$ \\
\hline Staff grade/associate specialist & $30(13)$ & $29(13)$ \\
\hline Not recorded & $34(15)$ & $20(9)$ \\
\hline \multicolumn{3}{|l|}{ Perioperative antibiotic: } \\
\hline No & $58(25)$ & $19(8)$ \\
\hline Yes & $165(71)$ & $192(83)$ \\
\hline \multicolumn{3}{|l|}{ Operated wrist: } \\
\hline Right & $101(440$ & $101(44)$ \\
\hline Left & $123(53)$ & $124(54)$ \\
\hline \multicolumn{3}{|l|}{ Intraoperative problems: } \\
\hline No & $222(96)$ & $219(95)$ \\
\hline Yes & $4(2)$ & $4(2)$ \\
\hline \multicolumn{3}{|c|}{ Surgeon experience (No of prior operations): } \\
\hline 0 & $0(0)$ & $1(0)$ \\
\hline$<5$ & $11(5)$ & $8(3)$ \\
\hline $5-10$ & $16(7)$ & $23(10)$ \\
\hline $11-20$ & $25(11)$ & $30(13)$ \\
\hline$>20$ & $171(74)$ & $158(68)$ \\
\hline Median (IQR) operation time (min) & $31(24-45)$ & $66(50-85)$ \\
\hline Median (IQR) length of stay (days) & $1(0-1)$ & $1(0-1)$ \\
\hline \multicolumn{3}{|l|}{ Wires } \\
\hline \multicolumn{3}{|l|}{ No of wires used: } \\
\hline 1 & $1(0)$ & - \\
\hline 2 & $96(42)$ & - \\
\hline 3 & $105(46)$ & - \\
\hline$>3$ & $5(2)$ & - \\
\hline \multicolumn{3}{|l|}{ Wire size $(\mathrm{mm})$ : } \\
\hline 1.6 & $187(81)$ & - \\
\hline 1.1 & $1(0)$ & - \\
\hline Other & $12(5)$ & - \\
\hline \multicolumn{3}{|l|}{ Technique } \\
\hline Kapandji & $54(23)$ & - \\
\hline Interfragmentry & $78(34)$ & - \\
\hline Mixed technique & $71(31)$ & - \\
\hline \multicolumn{3}{|l|}{ Plates } \\
\hline \multicolumn{3}{|l|}{ No of distal locking screws used: } \\
\hline 3 & - & $20(9)$ \\
\hline 4 & - & $62(27)$ \\
\hline 5 & - & $42(18)$ \\
\hline$>5$ & - & $88(38)$ \\
\hline \multicolumn{3}{|l|}{ Proximal screw } \\
\hline Locking & - & $103(45)$ \\
\hline Non-locking & - & $110(48)$ \\
\hline
\end{tabular}

IQR=interquartile range.

*Where numbers do not add to treatment group size, it indicates that some data were missing. 
Table 3| Means (SD) for main outcome measures 12 months after operation by treatment group (Kirschner wires or volar locking plate fixation), with estimated treatment effects after adjustment

\begin{tabular}{|c|c|c|c|c|c|c|c|}
\hline & \multicolumn{2}{|c|}{ Wire } & \multicolumn{2}{|c|}{ Plate } & \multicolumn{3}{|c|}{ Treatment effect estimates } \\
\hline & Mean (SD) & No of patients & Mean (SD) & No of patients & Raw & Adjusted $(95 \% \mathrm{Cl})^{*}$ & $P$ value \\
\hline \multicolumn{8}{|c|}{ Primary outcome PRWE score at 12 months in all participants } \\
\hline All participants & $15.3(15.8)$ & 211 & $13.9(17.1)$ & 204 & -1.4 & $-1.3(-4.5$ to 1.8$)$ & 0.398 \\
\hline \multicolumn{8}{|c|}{ Primary outcome PRWE score at 12 months in subgroups } \\
\hline Age $<50$ & $13.2(13.0)$ & 52 & $15.3(16.3)$ & 49 & 2.0 & $1.4(-5.0$ to 7.8$)$ & \multirow[t]{2}{*}{0.338} \\
\hline Age $\geq 50$ & $16.0(16.5)$ & 159 & $13.4(17.4)$ & 155 & -2.6 & $-2.2(-5.8$ to 1.4$)$ & \\
\hline No IA extension & $16.7(16.5)$ & 110 & $13.2(16.1)$ & 105 & -3.5 & $-3.3(-7.6$ to 1.1$)$ & \multirow[t]{2}{*}{0.211} \\
\hline IA extension & $13.8(14.9)$ & 101 & $14.7(18.2)$ & 99 & 0.9 & $0.7(-3.8$ to 5.2$)$ & \\
\hline \multicolumn{8}{|c|}{ Secondary outcomes at $\mathbf{1 2}$ months } \\
\hline DASH & $16.2(17.9)$ & 201 & $13.0(15.6)$ & 195 & -3.3 & $-3.2(-6.5$ to 0.0$)$ & 0.051 \\
\hline$E Q-5 D$ & $0.83(0.19)$ & 204 & $0.85(0.19)$ & 194 & 0.02 & $0.02(-0.02$ to 0.06$)$ & 0.353 \\
\hline
\end{tabular}

$\mathrm{IA}=$ intra-articular.

${ }^{*}$ Treatment effect estimate is difference between group means. Adjusted effect estimates from mixed effects regression based on complete case analysis with treatment group, age group, sex, and intra-articular extension as covariates (fixed effects) and recruiting centre as random effect; $P$ values from analysis of variance (ANOVA) $\mathrm{F}$ test. 
Table 4 | Counts ${ }^{\star}$ and rates of reported complications at 12 months after operation by treatment group (Kirschner wires (n=230) or volar locking plate fixation $(n=231)$, with estimated treatment effects after adjustment

\begin{tabular}{|c|c|c|c|c|c|c|c|}
\hline & \multicolumn{2}{|c|}{ No (\%) with events } & \multicolumn{2}{|c|}{ No (\%) without events } & \multicolumn{3}{|c|}{ Treatment effect estimates } \\
\hline & Wire & Plate & Wire & Plate & Raw & Adjusted $(95 \% \mathrm{Cl}) \dagger$ & $P$ value \\
\hline \multicolumn{8}{|l|}{ Cast and dressing } \\
\hline Cast after operation & $224(98)$ & $171(75)$ & $5(2)$ & $57(25)$ & 0.07 & $0.04(0.01$ to 0.11$)$ & $<0.001$ \\
\hline Dressing change & $12(5)$ & $11(5)$ & $215(93)$ & $219(95)$ & 0.90 & $0.89(0.37$ to 2.14$)$ & 0.792 \\
\hline Plaster change & $42(18)$ & $17(7)$ & $187(81)$ & $211(91)$ & 0.36 & $0.35(0.19$ to 0.64$)$ & $<0.001$ \\
\hline \multicolumn{8}{|c|}{ Postoperative complications } \\
\hline Refracture & $2(1)$ & $2(1)$ & $225(98)$ & $226(98)$ & 1.00 & $0.99(0.14$ to 7.18$)$ & 0.996 \\
\hline Neurological injury & $14(6)$ & $20(9)$ & $215(93)$ & $210(91)$ & 1.46 & $1.49(0.72$ to 3.09$)$ & 0.272 \\
\hline Vascular injury & 0 & 0 & $229(99)$ & $228(99)$ & - & - & - \\
\hline Tendon injury & $4(2)$ & $6(3)$ & $225(98)$ & $223(96)$ & 1.51 & 1.57 (0.39 to 6.39$)$ & 0.495 \\
\hline Superficial infection & $18(8)$ & $12(5)$ & $209(91)$ & $216(94)$ & 0.65 & 0.64 (0.30 to 1.37$)$ & 0.248 \\
\hline Deep infection & $1(<1)$ & $1(<1)$ & $226(98)$ & $227(99)$ & 1.00 & $0.90(0.06$ to 14.73$)$ & 0.942 \\
\hline \multicolumn{8}{|l|}{ Treatment } \\
\hline Antibiotics & $13(6)$ & $11(5)$ & 217 (93 & $220(95)$ & 0.84 & $0.84(0.37$ to 1.93$)$ & 0.684 \\
\hline $\begin{array}{l}\text { Removal of } \\
\text { metalwork }\end{array}$ & $7(3)$ & $11(5)$ & $223(98)$ & $220(95)$ & 1.59 & 1.58 (0.60 to 4.16$)$ & 0.347 \\
\hline Debridement & $2(1)$ & $1(<1)$ & $228(99)$ & $230(99)$ & 0.50 & $0.46(0.04$ to 5.19$)$ & 0.519 \\
\hline Revision & $5(2)$ & $2(1)$ & $225(98)$ & $226(99)$ & 0.39 & $0.38(0.06$ to 2.30$)$ & 0.235 \\
\hline
\end{tabular}

*Where numbers do not add to treatment group size, it indicates that some data were missing.

†Treatment effect estimate is odds ratio. Adjusted effect estimates from mixed effects logistic regression based on complete case analysis with treatment group, age group, sex, and intra-articular extension as covariates (fixed effects) and recruiting centre as random effect; $P$ values are from analysis of variance (ANOVA) $x^{2}$ test 


\section{Figures}

\begin{tabular}{|c|c|}
\hline \multicolumn{2}{|c|}{$\begin{array}{l}\text { Assessed for eligibility (18 UK Hospitals; January 2011-July 2012) } \\
\text { Sustained dorsally displaced fracture of distal radius (within } 3 \mathrm{~cm} \text { of radiocarpal joint) } \\
\text { Surgeon believes patient would benefit from operative fixation of fracture } \\
\text { Aged over } 18 \text { and presenting within } 2 \text { weeks of injury } \\
\text { Eligible ( } n=639 \text { ) }\end{array}$} \\
\hline \multicolumn{2}{|c|}{$\downarrow$} \\
\hline \multicolumn{2}{|c|}{$\begin{array}{ll}\text { Declined to participate }(n=178,28 \%) & \\
\text { Definitely wants Kirschner wires }(n=26,15 \%) & \text { Does not want to be part of research project }(n=55,31 \%) \\
\text { Definitely wants locking plate }(n=29,16 \%) & \text { No reason }(n=22,12 \%) \\
\text { Does not want surgery }(n=22,12 \%) & \text { Other }(n=24,14 \%)\end{array}$} \\
\hline \multicolumn{2}{|c|}{$\downarrow$} \\
\hline \multicolumn{2}{|c|}{ Randomised $(n=461)$} \\
\hline$\digamma$ & 7 \\
\hline $\begin{array}{l}\text { Kirschner wires }(n=230) \\
\text { As allocated }(n=208,90 \%) \\
\text { Patients received plates }(n=18) \text { : } \\
\text { Patient choice }(n=1) \\
\text { Perioperative surgeon choice }(n=16) \\
\text { Administrative error }(n=1) \\
\text { Other }(n=4) \text { : } \\
\text { Cast or MUA }(n=2) \\
\text { No operation }(n=1) \\
\text { Ulna and radial locking plates }(n=1)\end{array}$ & $\begin{array}{l}\text { Locking plate }(n=231) \\
\text { As allocated }(n=213,92 \%) \\
\text { Wires }(n=9) \text { : } \\
\text { Patient choice }(n=1) \\
\text { Perioperative surgeon choice }(n=6) \\
\text { Administrative error }(n=2) \\
\text { Other }(n=9) \text { : } \\
\text { Cast or MUA }(n=7) \\
\text { No operation }(n=1) \\
\text { Volar locking and dorsal plate }(n=1)\end{array}$ \\
\hline$\downarrow$ & $\downarrow$ \\
\hline $\begin{array}{l}\text { Loss to follow-up }(n=14) \text { : } \\
\text { Withdrawn }(n=3) \\
\text { Died }(n=3) \\
\text { Unresponsive (no post-baseline data) }(n=8)\end{array}$ & $\begin{array}{l}\text { Loss to follow-up }(n=15) \text { : } \\
\text { Withdrawn }(n=3) \\
\text { Died }(n=1) \\
\text { Unresponsive (no post-baseline data) }(n=11)\end{array}$ \\
\hline $\begin{array}{l}\text { Data completeness } \\
\text { Baseline }(n=229,99.6 \%) \\
3 \text { months }(n=212,92.2 \%) \\
6 \text { months }(n=208,90.4 \%) \\
12 \text { months }(n=211,91.7 \%)\end{array}$ & $\begin{array}{l}\text { Data completeness } \\
\text { Baseline }(n=229,99.1 \%) \\
3 \text { months }(n=211,91.3 \%) \\
6 \text { months }(n=206,89.2 \%) \\
12 \text { months }(n=205,88.7 \%)\end{array}$ \\
\hline
\end{tabular}

Fig 1 Overall flow of patients with dorsally displaced fracture of the distal radius in study of percutaneous fixation with Kirschner wires versus volar locking plate fixation. MUA=manipulation under anaesthesia

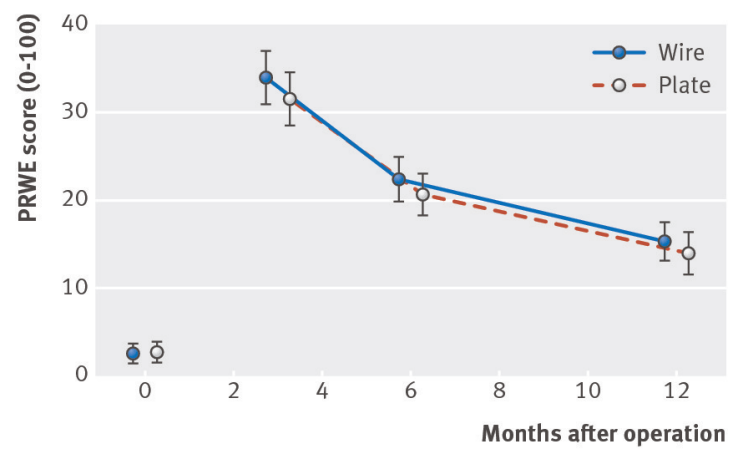

Fig 2 Scores over time on patient rated wrist evaluation (PRWE), with 95\% confidence intervals in patients with dorsally displaced fracture of the distal radius according to treatment with Kirschner wire fixation or locking plate fixation 